\title{
Power, IntraTeam Conflicts, Conflict Contagion and its Impact on Performance
}

\author{
Amina Malik, Haroon Aziz, Shahab Ud Din, Tanveer Ahmed \\ COMSATS University Islamabad, Wah Campus, Pakistan \\ Foundation University, Islamabad, Pakistan \\ amina_malik_2000@yahoo.com, haroonpvma@gmail.com,shahab@ciitwah.edu.pk, \\ tanvirkhan1979@yahoo.com
}

\begin{abstract}
The objective of this study is to examine the importance of power, intrateam conflict, conflict contagion and its impact on organizational performance. This study has used past literature to extend work on power, intrateam conflict, conflict contagion and its impact on performance by providing prepositions. The study demonstrates the importance of power and its impact on intrateam conflicts, which form the shape of conflict contagion and ultimately affect performance. Study found that power leads to more conflicts and its process of spreading hastens because of its contagious nature negatively influences the team's performance. The paper has highlighted the untapped element of power and creates a bridge between power, conflict and its impact on organizational performance. Many researchers have focused separately on power, teamwork and conflict. However, still, there is a need to assess whether individual power interests also takes the form of conflict contagion, which might affect performance of the organization.
\end{abstract}

Keywords: Power, Intrateam Conflicts, Conflict contagion, Performance

\section{Introduction}

In this era, emphasis on team effectiveness is the major area of concern in emerging organizations (Cohen \& Bailey, 1997). The concept of teamwork is used in organizing, structuring and allocation of tasks. Teamwork has not only increased performance (Ingram, 1996) but still, there is a need to assess, whether teams with power are effective or otherwise. As, the increasing trend of teamwork approach also poses some issues like conflict, which takes the form of contagion and sometimes affects performance.

Further, in order to create effective teams, it is of utmost importance to understand the relationship of power, intrateam conflict, conflict contagion and its impact on performance (Mannix \& Sauer, 2006). Earlier research was carried out with limited scope in seclusion from social problems (Lammers, Dubois, Rucker, \& Galinsky, 2013). A lot of literature exists on power and intrateam conflicts at the entity level (Bayazit \& Mannix, 2003; Kankanhalli, Tan, \& Wei, 2006, de Jong, Schalk, \& Curseu, 2008, Stewart \& Barrick, 2000). However, yet there is a need to inquire about the relationship between the concept of power and its relationship with intrateam conflict contagion and its impact on performance as this area is quite understudied. Further, there is also a need to focus on which attitudes and behaviors provoke in garnering power, which takes the form of conflict contagion or struggles to achieve power among the teammates and ultimately negatively affects performance.

This qualitative research study extends the existing body of literature in the area in the following ways: Firstly, this study extends the topic of power. Secondly, this research study develops a bridge between the impact of power on the conflict contagion in intrateam context. This area has become a pivotal area of research as mostly conflict arises in teams when people are dependent on others for achieving common goals. Thirdly, it broadens the horizon of power and studies its impact on the performance of the organization. Moreover, the findings of this study have important implications for executives, management and decision makers.

The rest of the paper is organized as follows. Section 2 describes the theoretical framework about power, conflict and its contagious nature and development of prepositions. Section 3 concludes the study and provides future research direction as well.

\section{Theoretical Framework}

Power: The history reveals that humans have an instinct for status as well as power in their behavior (Frieze \& Boneva, 2001). This intuition forces human being for constant struggle (Kipnis, 1976) Earlier literature 
provides many definitions of power. Winter (1973) defined power as independent command over the resources, without the dominance of the society. Power was also defined as the dominance of individual in agency context (Winter, 1973). Further, it is also defined as to get the result as per own aspiration (Winter, 1973). Overall, the concept of power is mainly about dominance.

Team Power: Team power is defined in terms of control of resources in entity or society as a whole (L. Greer \& van Kleef, 2008). Further, this concept is defined as complete control in the administration of resources as well as punishment (French, Raven, \& Cartwright, 1959). The individual behavior of making others realize that they belong to a certain class, also creates dominance culture (Guinote, Brown, \& Fiske, 2006). Moreover, the powerful post or position might result in dominance in terms of either respect or status (Anderson \& Berdahl, 2002; Guinote, Judd, \& Brauer, 2002). Diffusion in a team means a differentiation in the amount of resources held by the team members (Tarakci, Greer, \& Groenen, 2016). Further, research has also revealed that polite behavior diminishes as team members get power (Keltner, Young, Heerey, Oemig, \& Monarch, 1998). Some teams achieve a high level of power, which sometimes move the team towards negativity and also affect the performance of the team as well as organization. Earlier research also reveals that the probability of conflicts is higher in intragroup powerful teams (Hildreth \& Anderson, 2016). Zhao \& Greer (2017) also mentioned that powerful team members usually dominate and have quite hostile approach. They try to protect own power by using an aggressive approach, which sometimes makes other feel paranoid.

Conflict: Conflict is the name of struggle among parties who are inter-reliant but have contrary goals, sparse reward and intervention from other bodies in the attainment of goals (Wilmot \& Hocker, 2001). In earlier research, most of the researchers have focused on the negative impact of the conflict. Hackman \& Morris (1974) elaborated the concept of conflict in terms of its effect on the relationship at the individual as well as at the professional level. Whereas on the other side, the conflict has also a positive impact on the performance of the team. There are different stages when conflict arises, which include accommodation, compromise to a certain extent, solution of issues and sometimes complete avoidance (Deutsch, 1977). Auxiliary to some stages, some severities in conflict include bad voices, howling, shrieking and banging of doors (Jehn, 1997) . Further, conflict can have a negative effect on the innovation, novelty of ideas, performance, decision power and effective communication (De Dreu, 1997). Broadly, Jehn (1995) classified conflicts into two kinds at the intragroup level: task conflict and relationship conflict.

Task Conflict: Task conflict is defined as divergence of opinion among individuals on decisions. Main areas include difference of opinion on resources, processes and procedures, analysis and representation of results. On the one side, earlier research in student teams working on different tasks showed that members having high power performance was relatively worse than members having low power (Zhao \& Greer, 2017). Whereas, on the contrary, task conflict has a positive association with emergence of creativity and innovation (West \& Anderson, 1996), the occurrence of healthy debate on various issues (Jehn, Northcraft, \& Neale, 1999) and acceptability of group decisions (Amason, 1996).

Relationship Conflict: Relationship conflict arises due to incongruity among the persons and it leads to loathing. It includes divergence of opinion based on a value system, adherence of norms or difference on tastes on various aspects. Normally, relationship conflict has a negative impact on employees satisfaction level (De Dreu \& Van Vianen, 2001), which ultimately results in a reduction in an overall efficiency of the team (Jehn, 1997).

Process Conflict: Process conflict is a difference of opinion on the usage of strategy for attainment of the goal (Jehn \& Mannix, 2001). Further, process conflict arises when group members have a disagreement on tasking and distribution of assignments. Process conflict affects morale as well as performance and output (Jehn, 1997; Jehn et al., 1999).

Conflict Contagion: One of the major drawbacks of the team is interdependence, which increases the likely hood of conflict contagion process (Lewin, 1948). Further, this interdependent adds fuel to the conflict contagion. In teams, conflicts may spread from just a few to all team members over time, which might aggravate and spread aggressively and takes the shape of conflict contagion. Lau \& Murnighan (1998) hypothesized that sub groupings might form on the basis of demographic characteristics. Further, 
demographic influence on the team may also increase the intensity of coalition formation in a team, which might hasten conflict and takes the shape of dyadic conflict. We propose the following mechanisms for conflict contagion:-

Coalition Formation: The first primary mechanism we suggest is coalition formation. We believe that underlying reasons for coalition formation are preceding relationships and conflicts. The intensity of coalition formation is also based on access to resources. Further, members who are particularly close to members directly engaged in the start of conflict may feel that they should support them. Further, research has also revealed that team members always customize their behavior with members having socially same background (Crano \& Cooper, 1973).

Emotional Contagion: Second primary mechanism we propose is emotional contagion. We suggest that emotional contagion is a situation when team members get involved in conflicts in which they were not originally engaged; which might be due to the spread of negativity. Further, these negative emotions might be the source of emotional contagion (Bodtker \& Katz Jameson, 2001). Further, conflicts take place due to perceived incompatibilities, which affects the outcome (Roseman, 1996; Bell \& Song, 2005). They include disappointment, dislike and annoyance (Guetzkow \& Gyr, 1954; Russell, 1978). Negative emotions also affect other team members and take the shape of emotional contagion (Barsade, 2002; Kelly \& Barsade, 2001), which also aggravate the situation and ultimately affect the performance.

Defense of own and Team Interests: Lastly, the third primary mechanism we propose is the member's defense of their own and team vested interests. When conflict arises in a team and individuals are forced to show their self-defense and take certain measures. In the following sections, we will explain in detail how each of these mechanisms of conflict contagion can take place and the factors which can exacerbate or ameliorate the speed and extent to which they may contribute to conflict contagion and its outcomes.

Linkage between Team Power and Intrateam Conflict: The most widely used definition for construct of power is control over the resources (Blau, 1964). Further, power is also defined in terms of control over the behaviors as well as outcomes (Keltner, Gruenfeld, \& Anderson, 2003). It is generally perceived that teams with high power, function relatively better due to their wide exposure and knowledge base (Lazear \& Rosen, 1979). But on other side, it is also suspected that high-power teams may perform worse as compared to lowpower teams due to conflicts (De Dreu \& Weingart, 2003).

Linkage between team power and performance: An important determinant of team performance is openness, which not only affects productivity, cooperation and performance. Further, team power has some damaging effects on team performance, which includes a reduction in communication among the teammates. Mainly, in team setting power affects performance in two ways. Firstly, in psychological context power leads among individuals influence their attitudes and opinions in group settings (Berdahl \& Martorana, 2006; Anderson \& Berdahl, 2002; Berdahl \& Martorana, 2006). Secondly, individuals who come in power undervalue the viewpoint and judgment of other members (Berdahl \& Martorana, 2006). This type of dominating behavior has a devastating impact on the performance. We, therefore, expect that leaders with a highly skewed sense of power have dominating team interactions. Thus, we predict and propose the following:

Proposition 1: High-power teams have higher levels of conflict (task, process, relationship) than lowpower teams and impact performance.

Based on existing literature (De Dreu, 2008), it is further suggested that various nature of conflicts negatively affects team performance. Further, the theoretical mechanisms addressing this area shows that conflicts may create distractions and ultimately affect the attainment of goals, which ultimately decrease the productivity of the team and efficiency of the system (Evan, 1965, Jehn \& Bendersky, 2003). These incompatibilities increase conflict, which creates negative emotions including annoyance, dislike and rage (Bell \& Song, 2005). These conflicts can badly affect the cognitive ability of team members (Brief \& Weiss, 2002). 
Keeping in view the discussion above, it is proposed that high power teams are prone to various nature of conflicts including task, process and relationship conflicts as compared to lower power teams, because of rivalry between teammates for attainment of power (Chattopadhyay, Finn, \& Ashkanasy, 2010, Greer \& van Kleef, 2010). Further, individuals who have an appetite for high power teams may come across many hindrances. Earlier research reveals that tense power dynamic in high-power teams in high-level teams is especially receptive to imbalance pertaining to power, perks and prestige (Greer \& van Kleef, 2010; Siegel \& Hambrick, 2005). Further, high power members also become aggressive, dominating and rude when dealing with the teammates (Morrison, Fast, \& Ybarra, 2009, Chattopadhyay, Finn, \& Ashkanasy, 2010). Moreover, research has also revealed that persons in powerful team are not only harsh, but are more vulnerable to conflict (Smith, Jost, \& Vijay, 2008). Therefore, negativity and conflict aggravate, especially in high power teams. Consequently, strive for attaining power increases the likelihood of conflict including task, process and relationship conflict. Therefore, based on above theoretical mechanisms we propose that conflict and team performance will be negatively related.

\section{Proposition 2: Conflict Contagion spread and involves other team members and has a negative impact on the team performance}

Teams having tendency of conflict might result in affecting the performance. Focus on main goal decreases when conflict takes the form of conflict contagion and spread around (Kelly \& Barsade, 2001). Conflict widens the communication gaps, which is also a contributor in affecting performance (Baron, 1991) and it increases animosity level (Friedman, Tidd, Currall, \& Tsai, 2000). Conflict may proceed either in linear way or else take the form of riot (Gersick, 1988). Conflict contagion might increase the division among the team (Li and Hambrick, 2005; Molleman, 2005, Hogg et al., 1990), give rise to inter-subgroup competition (Lau and Murnighan, 1998), and behavioral collapse (Li and Hambrick, 2005). Such type of negative conflict contagion may detract members from the goal and ultimately affect team performance. The competition among the polarized team may take precedence over the likely advantage of the conflict. The competitive relations among teammates results in the maltreatment like bullying of other team members results in affecting performance (Boswell and Olson-Buchanan, 2004).

\section{Conclusion}

This study demonstrates the importance of power, intrateam conflicts, conflict contagion and their impact on performance. We have highlighted the untapped element of power from conflict0000s and its impact on organization. We have found that power leads to more conflicts and its process of spreading hastens because of its contagious nature and it negatively influences the performance of the teams. The findings show that intensity of conflict is higher in high power teams. Further, conflict contagion spread over and negatively affects the performance of the team as a whole.

Based on these results, some timely steps should be taken with a view to improve conflict management in teams. Moreover, the most important thing is diagnosis of conflict, so that timely remedial measure can be taken to handle the situation. Secondly, management should involve members in open discussions of issues, by also observing the limits, to increase the acceptance level of decisions among the members and to reduce conflicts. Further, management should take measures to mitigate conflicts as soon as possible. Thirdly, extraordinary attention should be given to the stage of conflict because of its interactive effects on performance and contagious process of spreading. The findings of this study extend the existing body of literature on 0the conflict by creating a bridge between conflict, power and its contagion effect on performance. This research work builds on emerging and sweltering body of research area and moves it from conventional approach of exploring individual topics to extended variables in the area.

Future Research: Future research could be undertaken by examining the factors accelerating the conflict contagion. Further, future research can also tap factors increasing the momentum of conflict contagion and how it can be prevented. 


\section{References}

Amason, A. C. (1996). Distinguishing the effects of functional and dysfunctional conflict on strategic decision making: Resolving a paradox for top management teams. Academy of Management Journal, 39(1), 123-148.

Anderson, C., \& Berdahl, J. L. (2002). The experience of power: examining the effects of power00000 on approach and inhibition tendencies. Journal of Personality and Social Psychology, 83(6), 1362.

Baron, R. A. (1991). Positive effects of conflict: A cognitive perspective. Employee Responsibilities and Rights Journal, 4(1), 25-36.

Barsade, S. G. (2002). The ripple effect: Emotional contagion and its influence on group behavior. Administrative Science Quarterly, 47(4), 644-675.

Bayazit, M., \& Mannix, E. A. (2003). Should I stay or should I go? Predicting team members' intent to remain in the team. Small Group Research, 34(3), 290-321.

Bell, C., \& Song, F. (2005). Emotions in the conflict process: An application of the cognitive appraisal model of emotions to conflict management. International Journal of Conflict Management, 16(1), 30-54.

Berdahl, J. L., \& Martorana, P. (2006). Effects of power on emotion and expression during a controversial group discussion. European Journal of Social Psychology, 36(4), 497-509.

Blau, P. M. (1964). Exchange and power in social life. New Brunswick: NJ: Transaction Publishers.

Bodtker, A. M., \& Katz Jameson, J. (2001). Emotion in conflict formation and its transformation: Application to organizational conflict management. International Journal of Conflict Management, 12(3), 259-275.

Brief, A. P., \& Weiss, H. M. (2002). Organizational behavior: Affect in the workplace. Annual review of psychology, 53(1), 279-307.

Chattopadhyay, P., Finn, C., \& Ashkanasy, N. M. (2010). Affective responses to professional dissimilarity: A matter of status. Academy of Management Journal, 53(4), 808-826.

Cohen, S. G., \& Bailey, D. E. (1997). What makes teams work: Group effectiveness research from the shop floor to the executive suite. Journal of Management, 23(3), 239-290.

Crano, W. D., \& Cooper, R. E. (1973). Examination of Newcomb's extension of structural balance theory.

De Dreu, C. K. (1997). Productive conflict: The importance of conflict management and conflict issue. Using Conflict in Organizations, 9-22.

De Dreu, C. K. (2008). The virtue and vice of workplace conflict: Food for (pessimistic) thought. Journal of Organizational Behavior, 29(1), 5-18.

De Dreu, C. K., \& Van Vianen, A. E. (2001). Managing relationship conflict and the effectiveness of organizational teams. Journal of Organizational Behavior, 22(3), 309-328.

De Dreu, C. K., \& Weingart, L. R. (2003). Task versus relationship conflict, team performance, and team member satisfaction: a meta-analysis. Journal of Applied Psychology, 88(4), 741.

de Jong, R., Schalk, R., \& Curseu, P. L. (2008). Virtual communicating, conflicts and performance in teams. Team Performance Management: An International Journal, 14(7/8), 364-380.

Deutsch, M. (1977). The resolution of conflict: Constructive and destructive processes: Yale University Press.

Evan, W. M. (1965). Conflict and performance in R \& D organizations. IMR; Industrial Management Review (pre-1986), 7(1), 35.

French, J., Raven, B., \& Cartwright, D. (1959). The bases of social power. Classics of Organization Theory, 7, 311-320.

Friedman, R. A., Tidd, S. T., Currall, S. C., \& Tsai, J. C. (2000). What goes around comes around: The impact of personal conflict style on work conflict and stress. Int. Journal of Conflict Management, 11(1), 32-55.

Frieze, I. H., \& Boneva, B. S. (2001). Power motivation and motivation to help others. The use and abuse of power: Multiple Perspectives on the Causes of Corruption, 75-89.

Gersick, C. J. (1988). Time and transition in work teams: Toward a new model of group development. Academy of Management Journal, 31(1), 9-41.

Greer, L., \& van Kleef, G. A. (2008). Power Distance, Conflict Resolution and Status Conflicts in Teams: How Do Team Power Dynamics Impact Conflict Resolution?

Greer, L. L., \& van Kleef, G. A. (2010). Equality versus differentiation: The effects of power dispersion on group interaction. Journal of Applied Psychology, 95(6), 1032.

Guetzkow, H., \& Gyr, J. (1954). An analysis of conflict in decision-making groups. Human relations.

Guinote, A., Brown, M., \& Fiske, S. T. (2006). Minority status decreases sense of control and increases interpretive processing. Social Cognition, 24(2), 169-186.

Guinote, A., Judd, C. M., \& Brauer, M. (2002). Effects of power on perceived and objective group variability: evidence that more powerful groups are more variable. Journal of Personality and Social Psychology, 82(5), 708. 
Hackman, J. R., \& Morris, C. G. (1974). Group tasks, group interaction process, and group performance effectiveness: A review and proposed integration: Citeseer.

Hildreth, J. A. D., \& Anderson, C. (2016). Failure at the top: How power undermines collaborative performance. Journal of Personality and Social Psychology, 110(2), 261.

Ingram, H. (1996). Linking teamwork with performance. Team Performance Management: An International Journal, 2(4), 5-10.

Jehn, K. A. (1995). A multimethod examination of the benefits and detriments of intragroup conflict. Administrative Science Quarterly, 256-282.

Jehn, K. A. (1997). A qualitative analysis of conflict types and dimensions in organizational groups. Administrative Science Quarterly, 530-557.

Jehn, K. A., \& Bendersky, C. (2003). Intragroup conflict in organizations: A contingency perspective on the conflict-outcome relationship. Research in Organizational Behavior, 25, 187-242.

Jehn, K. A., \& Mannix, E. A. (2001). The dynamic nature of conflict: A longitudinal study of intragroup conflict and group performance. Academy of Management Journal, 44(2), 238-251.

Jehn, K. A., Northcraft, G. B., \& Neale, M. A. (1999). Why differences make a difference: A field study of diversity, conflict and performance in workgroups. Administrative Science Quarterly, 44(4), 741-763.

Kankanhalli, A., Tan, B. C., \& Wei, K.-K. (2006). Conflict and performance in global virtual teams. Journal of Management Information Systems, 23(3), 237-274.

Kelly, J. R., \& Barsade, S. G. (2001). Mood and emotions in small groups and work teams. Organizational Behavior and Human Decision Processes, 86(1), 99-130.

Keltner, D., Gruenfeld, D. H., \& Anderson, C. (2003). Power, approach, and inhibition. Psychological Review, $110(2), 265$.

Keltner, D., Young, R. C., Heerey, E. A., Oemig, C., \& Monarch, N. D. (1998). Teasing in hierarchical and intimate relations. Journal of Personality and Social Psychology, 75(5), 1231.

Kipnis, D. (1976). The powerholders.

Lammers, J., Dubois, D., Rucker, D. D., \& Galinsky, A. D. (2013). Power gets the job: Priming power improves interview outcomes. Journal of Experimental Social Psychology, 49(4), 776-779.

Lau, D. C., \& Murnighan, J. K. (1998). Demographic diversity and faultlines: The compositional dynamics of organizational groups. Academy of Management Review, 23(2), 325-340.

Lazear, E. P., \& Rosen, S. (1979). Rank-order tournaments as optimum labor contracts: National Bureau of Economic Research Cambridge, Mass., USA.

Lewin, K. (1948). In GW Lewin (Ed.), Resolving social conflicts; selected papers on group dynamics: New York: Harper \& Row.

Mannix, E. A., \& Sauer, S. J. (2006). Status and power in organizational group research: Acknowledging the pervasiveness of hierarchy. Advances in Group Processes, 23, 149-182.

Morrison, K. R., Fast, N. J., \& Ybarra, O. (2009). Group status, perceptions of threat, and support for social inequality. Journal of Experimental Social Psychology, 45(1), 204-210.

Roseman, I. J. (1996). Appraisal determinants of emotions: Constructing a more accurate and comprehensive theory. Cognition \& Emotion, 10(3), 241-278.

Russell, J. A. (1978). Evidence of convergent validity on the dimensions of affect. Journal of Personality and Social Psychology, 36(10), 1152.

Siegel, P. A., \& Hambrick, D. C. (2005). Pay disparities within top management groups: Evidence of harmful effects on performance of high-technology firms. Organization Science, 16(3), 259-274.

Smith, P. K., Jost, J. T., \& Vijay, R. (2008). Legitimacy crisis? Behavioral approach and inhibition when power differences are left unexplained. Social Justice Research, 21(3), 358-376.

Stewart, G. L., \& Barrick, M. R. (2000). Team structure and performance: Assessing the mediating role of intrateam process and the moderating role of task type. Academy of Management Journal, 43(2), 135-148.

Tarakci, M., Greer, L. L., \& Groenen, P. J. (2016). When does power disparity help or hurt group performance? Journal of Applied Psychology, 101(3), 415.

West, M. A., \& Anderson, N. R. (1996). Innovation in top management teams. Journal of Applied Psychology, $81(6), 680$.

Wilmot, W. W., \& Hocker, J. L. (2001). Interpersonal conflict: McGraw-Hill New York.

Winter, D. G. (1973). The power motive.

Zhao, E. Y., \& Greer, L. L. (2017). When the Powerful is Paranoid: Effects on Power Struggles, and Performance. Paper presented at the Academy of Management Proceedings. 